\title{
Effect of Pretreatment with Cilostazol on Spinal Cord Ischemia-reperfusion Injury in Rats
}

\author{
(D) Ülkü Kafa Kulaçoğlu1 ${ }^{1}$ (1) Yusuf Kalko², (D) Gözde Erkanlı Şentürk³ \\ 1 University of Health Sciences Turkey, İstanbul Mehmet Akif Ersoy Thoracic and Cardiovascular Surgery Training and Research Hospital, \\ Clinic of Cardiovascular Surgery, istanbul, Turkey \\ 2 istinye University Hospital, Department of Cardiovascular Surgery, istanbul, Turkey \\ 3istanbul University-Cerrahpaşa, Cerrahpaşa Faculty of Medicine, Department Histology and Embryology, Istanbul, Turkey
}

\section{Abstract}

Objective: Following the aortic aneurysm repair surgery, ischemic spinal cord injury is a substantial complication which may lead to paraplegia. This study aims to explore the protective effect of cilostazol, which is a phosphodiesterase type-3 inhibitor, against ischemic/ reperfusion-induced spinal cord injury that is experimentally forged in medulla spinalis of rats.

Methods: A total of 24 rats were separated into three workgroups. The control group $(n=8)$; the ischemic group ( $n=8)$, in which aortic clamping was performed without cilostazol administration; and finally the cilostazol-adminsistered group $(n=8)$. Each mouse was subjected to induced ischemia for 45 min by clamping of the abdominal aorta. Afterwards, blood build up was provided by de-clamping. Serial assessments of motor and sensory functions of all rats were performed prior to the operation and, at 24 and $48 \mathrm{~h}$ of reperfusion, using the Tarlov and LeMay scores. Later on, spinal cord tissues were collected for histopathologic examination.

Results: Tarlov scores at postoperative hours 24 and 48 tend to be significantly higher in the cilostazol-treated group than in the non-treated ischemia group ( $3.13 \pm 0.64$ versus $1.25 \pm 0.71, p=0.0029$ for the $24^{\text {th }}$ hour; $2.75 \pm 0.71$ versus $0.38 \pm 0.52, p=0.0016$ for the $48^{\text {th }}$ hour). LeMay scores at postoperative hours 24 and 48 were as well significantly higher in the cilostazol-treated group than in the non-treated ischemia group ( $9.13 \pm 1.13$ versus $4.50 \pm 0.76, p=0.0018$ for the $24^{\text {th }}$ hour; $9.00 \pm 1.20$ versus $3.75 \pm 0.89, p=0.0018$ for the $48^{\text {th }}$ hour). Histologic outcomes were strongly correlated to the neurologic outcomes.

Conclusion: These results suggest that pre-ischemia cilostazol treatment has a protective effect against ischemia/reperfusion-induced spinal cord injury.

Keywords: Ischemia/reperfusion, spinal cord injury, cilostazol, rat, animal model

\section{INTRODUCTION}

Due to the medulla spinalis's exposure of temporary or permanent ischemia during the surgery, paraplegia is undoubtedly one of the most important emerging and undesirable complications that might result after thoracoabdominal aneurysm repair surgeries (1). Lintott et al. (2) reported the frequency of paraplegia occurrence due to extended clamp durations, dissection, and rupture. Eventhough every procedure has been performed during surgery to ensure continuous perfusion of the medulla spinalis, paraplegia could be inevitable $(3,4)$. The damage mechanism caused by the reperfusion after ischemia is not clearly known. Increase in lipid peroxidation after reperfusion and neuronal damage secondary to fiber degeneration and results in loss of motor functions. 
Cilostazol is known as a selective inhibitor of cyclic nucleotide phosphodiesterase 3 (PDE3) (5). Intracellular cyclic adenosine monophosphate (CAMP) levels increase due to the inhibition of PDE3 activity and the decrease in CAMP degradation which results in diminished thrombocyte aggregation and vasodilatation. Besides, the pleiotropic effects of cilostazol have been used for the prevention of clinical disorders like recurrent stroke, coronary artery disease, and peripheral occlusive disease $(6,7)$. The pre-clinical studies where vasodilator and antiplatelet effects of cilostazol were presented are the determinants of these indications (5-7). This study explores the prophylactic properties of cilostazol on neurobehavioral disorders and histopathological changes observed due to experimentally induced ischemic/ reperfusion in spinal cord injury on rats.

\section{METHODS}

Istanbul University Animal Experiments Local Ethics Committee approval were obtained during the study (decision no: 145, date: 09.11.2009). The rats were exposed to $12 \mathrm{~h}$ of daylight as well as $12 \mathrm{~h}$ of darkness cycle. The shelter environment temperature was $\left(20^{\circ} \mathrm{C}-22^{\circ} \mathrm{C}\right)$ and humidity was $(50-60 \%)$ where standard rat feed and enough water was provided as well.

\section{Experimental Design}

$5 \mathrm{mg} / \mathrm{kg}$ xylazine (Rompun, Bayer, Istanbul, Turkey) and $60 \mathrm{mg} /$ kg ketamine (Ketalar, Parke-Davis Eczacıbasi, Istanbul, Turkey) were both used simultaneously for anesthesia. No mechanical ventilator was needed to support the animals' respiration during the experiment. A single $15 \mathrm{mg} / \mathrm{kg}$ dose of cefazolin (Cefamezin, Eczacibasi, Istanbul, Turkey) was administered in the postoperative period. During the experiment, these mice were administered $0.9 \% \mathrm{NaCl}$ intravenously for volume replacement. After sterilization of the operation site, the abdominal aorta was attained via a transperitoneal approach through a $10-\mathrm{cm}$ incision from the midline.

The cross clamp was placed after $100 \mathrm{U} / \mathrm{kg}$ systemic heparinization for anticoagulation. The aorta was crossclamped by the use of aneurysm clips. During the procedure a surgical microscope was used. These clips were placed below the renal artery and above the iliac bifurcation. After $45 \mathrm{~min}$, follows removal of the cross clamp. With the help of 4-Fr indwelling catheters placed beneath and above the clamp, distal and proximal aortic pressures were monitored. The incision was closed in layers. The control group was subjected to the exact surgical procedure except for aortic cross clamping. Before being placed in their cages.
The rodents were placed in a plastic box at $28{ }^{\circ} \mathrm{C}$ for $3 \mathrm{~h}$ to recover after the surgery.

Study groups: Twenty-four wistar-Albino male rats (weight 370$480 \mathrm{~g}$ ) were divided into three different groups, as follows:

1. Sham group $(n=8)$ : The operation was performed with similar conditions except for aortic clamping.

2. Ischemia group $(n=8)$ : The operation was performed with similar conditions including aortic clamping for $45 \mathrm{~min}$.

3. Cilostazol group ( $\mathrm{n}=8)$ : Cilostazol $(100 \mathrm{mg} / \mathrm{kg})$, dissolved in dimethyl sulfoxide, was injected intraperitoneally $2 \mathrm{~h}$ prior to operation. The surgery was performed in similar conditions including aortic clamping for $45 \mathrm{~min}$.

\section{Evaluation of the Neurobehavioral Outcome}

Evaluations of the motor and sensory functions in the hind limbs of the rats was performed prior to surgery and after $24^{\text {th }}$ and $48^{\text {th }}$ hours of reperfusion. While measuring, it was assessed using the LeMay score and Tarlov scale $(8,9)$. The Tarlov motor scale is read as follows: 0 , complete paraplegia; 1 , slight movement in the joint; 2, enough mobility in the joint but an inability to stand; 3, able to stand and able to walk; and 4, complete recovery. The LeMay score was calculated using a 15-point spinal cord performance scale. Motor-sensory deficits of the animals are evaluated using an index for each animal at each point in time (Appendix 1). The maximum deficit calculated by the LeMay score was 15 . The rats ( $n=8$ per group) were assigned to be killed after the second neurobehavioral assessment (48 ${ }^{\text {th }}$ hour). The rodents were killed by a high dose injection of sodium pentothal $(200 \mathrm{mg} / \mathrm{kg}$ ). The rapidly collected spinal tissues were placed in $10 \%$ formaldehyde at $4{ }^{\circ} \mathrm{C}$ for $48 \mathrm{~h}$.

\section{Histopathological Analysis}

Spinal cord samples were taken out from the $10 \%$ formaldehyde after $48 \mathrm{~h}$ fixation period. The specimens were dehydrated by placing them in $95 \%$ alcohol for $30 \mathrm{~min}$, then four changes were applied for $1 \mathrm{~h}$ each in $100 \%$ alcohol and five changes of toluene for $1 \mathrm{~h}$ each in a vacuum at $37^{\circ} \mathrm{C}$. After the spinal cords were infiltrated with paraffin, they were embedded in paraffin at 60 ${ }^{\circ} \mathrm{C}$ under vacuum and pressure. Transverse sections have been examined with a microtome. Five-micrometer sections were obtained through the spinal cord. Sections were deparaffinized and stained with cresyl violet, hematoxylin \& eosin, Luxol Fast Blue staining (to check for the integrity of the myelin structure) and studied using light microscopy. Histopathologic changes of the ventral motor horn cells in medulla spinalis were scored on a 3-point scale for motor deficits, myelin injury, edema, 
ependymal cell injury, vasocongestion as follows: 0 , no damage; 1, mild lesion $(<10 \%)$ observed; 2 , a moderate lesion $(10 \%$ to $50 \%$ ) observed; 3 , a severe lesion (>50\%) observed. A blind study was done with the neuropathologist who was unaware of the experimental conditions.

\section{Statistical Analysis}

The results obtained were reported as means \pm standard deviation. Data analysis was performed using the Statistical Package for Siocial Sciences version 14.0. Non-parametric tests such as Mann-Whitney U tests, Kruskal-Wallis tests, Spearman's correlation analyses, linear regression analysis, and paired Wilcoxon tests were carried out. Bonferroni correction was used where appropriate. P values of less than 0.05 were considered statistically significant.

\section{RESULTS}

The surgery was well tolerated by every mice. The mean proximal arterial pressure and mean distal arterial pressure values revealed no difference among study groups ( $p=0.840$, and $p=0.982$, respectively) (Table 1 ).

\begin{tabular}{|l|l|l|l|l|}
\hline \multicolumn{4}{|c|}{ Table 1. Hemodynamic differences with respect to groups } \\
\hline $\begin{array}{l}\text { Arterial } \\
\text { pressure }\end{array}$ & $\begin{array}{l}\text { Sham } \\
\text { group }\end{array}$ & $\begin{array}{l}\text { Ischemia } \\
\text { group }\end{array}$ & $\begin{array}{l}\text { Cilostazol } \\
\text { group }\end{array}$ & p value \\
\hline $\begin{array}{l}\text { Mean proximal } \\
\text { arterial } \\
\text { pressure, } \\
\text { mmHg }\end{array}$ & $79.38 \pm 1.06$ & $79.13 \pm 0.83$ & $79.25 \pm 1.04$ & $p=0.840$ \\
\hline $\begin{array}{l}\text { Mean distal } \\
\text { arterial } \\
\text { pressure, } \\
\text { mmHg }\end{array}$ & $10.88 \pm 0.83$ & $10.75 \pm 1.04$ & $10.75 \pm 1.04$ & $p=0.982$ \\
\hline
\end{tabular}

For each group, neurological examinations were performed during the $24^{\text {th }}$ and $48^{\text {th }}$ hours. For each group, Tarlov scores (Table 2) and LeMay scores (Table 3) revealed no difference between two-time points ( $24^{\text {th }}$ and $48^{\text {th }}$ hours of reperfusion) $(p=0.07368$ and $p=0.160$, respectively).

Histopathological analysis revealed a significant difference among study groups $(p<0.05)$ (Table 4$)$. While no significant damage was observed in the neurons in the sham-operated animal group, neuronal damage was detected in the control group rodents.

On the contrary, pretreatment with cilostazol was found to significantly reduce the histologic changes. Motor deficits, myelin injury, ependymal cell injury, and vasocongestion were found to be significantly lower in the cilostazol-treated group than in the non-treated ischemic group ( $p=0.0079, p=0.0023$, $p=0.0200$, and $p=0.0104$, respectively). Regarding edema, both groups did not differ from each other significantly $(p=0.1268)$ (Table 4) (Figure 1-3).

\section{DISCUSSION}

In this study, the transient ischemia-induced spinal cord ischemia (SCl) was significantly attenuated in rats that received cilostazol, (a type III phosphodiesterase inhibitor) compared with control animals. Cilostazol also prevented histologic changes induced by the transient ischemia, such as motor deficits, myelin injury, ependymal cell injury, and vasocongestion, both 24 and $48 \mathrm{~h}$ after the ischemia.

Ischemic spinal cord injury secondary to clamping the aorta may occur during thoracoabdominal aortic aneurysm and

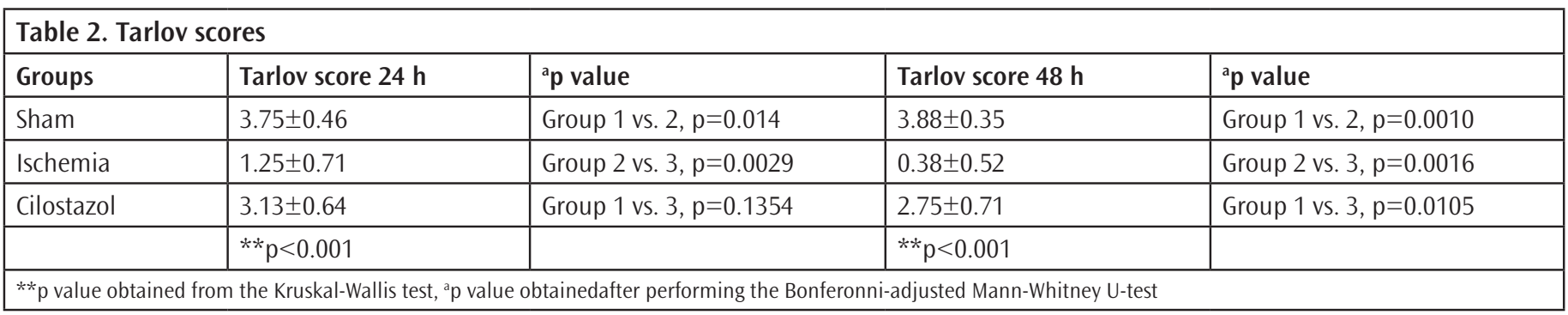

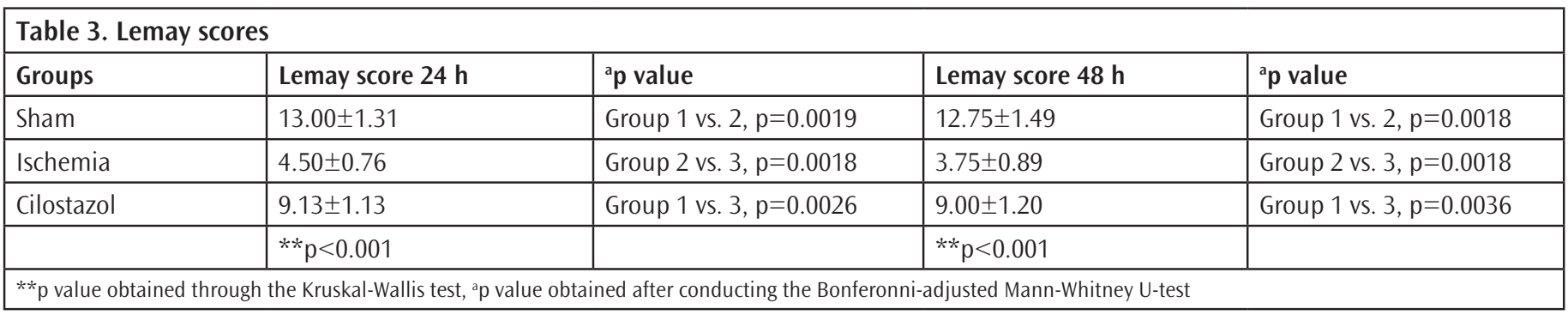


dissecting operations. As a result, paraplegia may develop. In experimentally induced $\mathrm{SCl}$, while oxidative stress does not permit antioxidant activity, local antioxidants protect the neural tissue from oxidative stress. Reperfusion occurs 1-2 days after $\mathrm{SCl}$, exacerbating the neural damage (8-10).

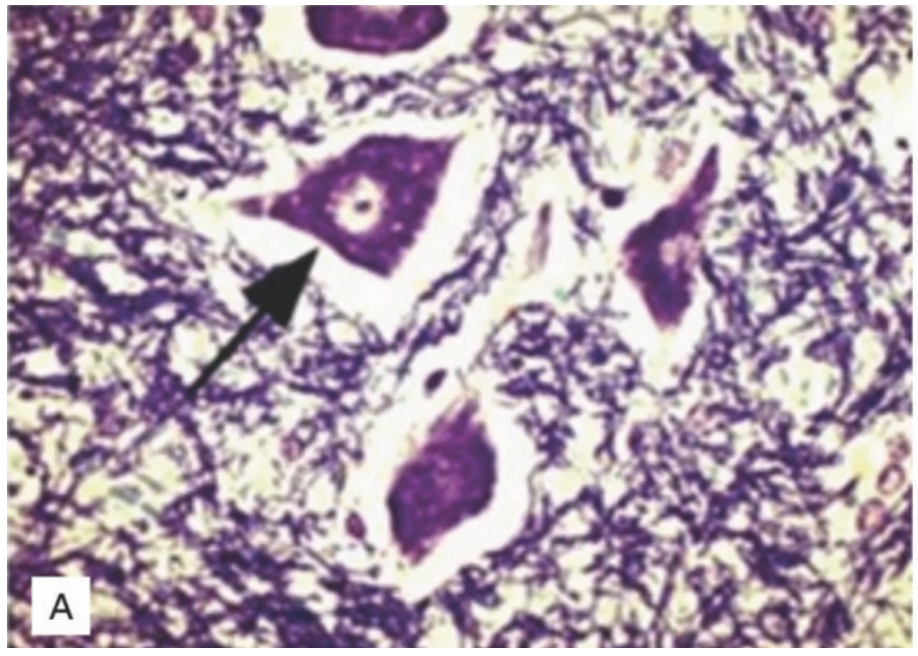

It is well known that, oxidative stress triggers the lipid peroxidation cascade resulting in cell membrane damage after a couple of days following SCI $(11,12)$. Treatments which decrease oxidative stress might provide benefit for neurological diseases (13). The central nervous system which is well recognized for its rich lipid composition I is more prone to damage as a result of

Figure 1. Group 1 (control group); normal morphology (A), nerve cells (arrow) (B), ependymal cells (arrowhead) and vascular structure $\left(^{*}\right)$ are observed. (A) Luxol fast blue (Kluver Berrare) stain x100; (B) hematoxylin \& eosin stain x100; insert: x400
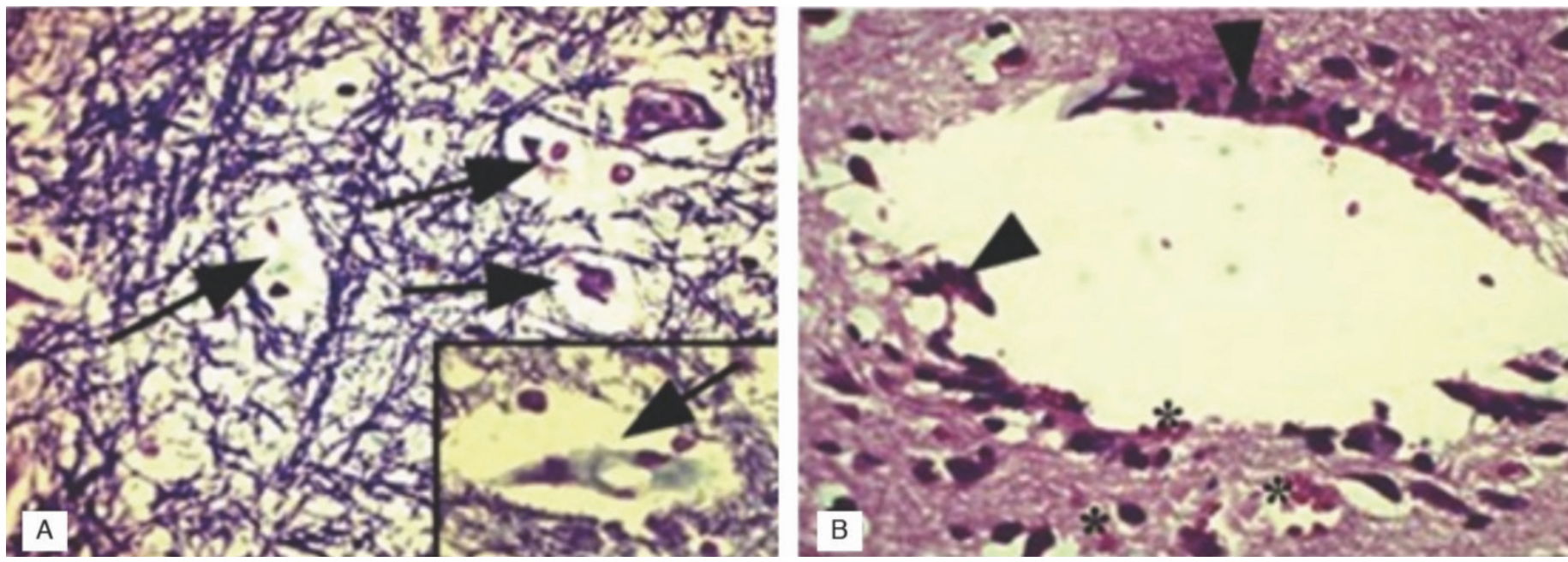

Figure 2. In group 2 (ischemia group); (A) damaged nerve cells (arrow), diminished myelination, (A) damaged ependymal cells (arrowhead) and vasocongestion (*) are seen. (A) Luxol fast blue (Kluver Berrare) stain x100; (B) hematoxylin \& eosin stain x100; insert: x400

\begin{tabular}{|l|l|l|l|l|l|}
\hline Table 4. Comparison of histopathological score among groups \\
\hline Groups & Motor deficits & Myelin injury & Edema & Ependimal cell injury & Vasocongestion \\
\hline Group 1 & $0.00 \pm 0.00$ & $0.13 \pm 0.35$ & $0.13 \pm 0.35$ & $0.13 \pm 0.35$ & $0.00 \pm 0.00$ \\
\hline Group 2 & $2.25 \pm 0.46$ & $2.13 \pm 0.35$ & $1.75 \pm 0.71$ & $2.63 \pm 0.52$ & $2.50 \pm 0.53$ \\
\hline Group 3 & $1.25 \pm 0.46$ & $1.13 \pm 0.35$ & $1.13 \pm 0.35$ & $1.75 \pm 0.46$ & $1.38 \pm 0.52$ \\
\hline Group 1 vs. 2 & $\mathrm{p}=0.0006$ & $\mathrm{p}=0.0007$ & $\mathrm{p}=0.0020$ & $\mathrm{p}=0.0010$ & $\mathrm{p}=0.0008$ \\
\hline Group 2 vs. 3 & $\mathrm{p}=0.0079$ & $\mathrm{p}=0.0023$ & $\mathrm{p}=0.1268$ & $\mathrm{p}=0.0200$ & $\mathrm{p}=0.0104$ \\
\hline Group 1 vs. 3 & $\mathrm{p}=0.0006$ & $\mathrm{p}=0.0023$ & $\mathrm{p}=0.0023$ & $\mathrm{p}=0.0013$ & $\mathrm{p}=0.0007$ \\
\hline
\end{tabular}


lipid peroxidation resulting from free radicals. The purpose of neuroprotection is to prevent neurons from lipid peroxidation occurring after SCl (14).

This study discloses a neuroprotective effect of cilostazol in an in vivo $\mathrm{SCl}$ model. To protect the spinal cord from the ischemic damage due to distal aortic perfusion, drainage of the cerebrospinal fluid, reimplantation of the intercostal arteries, and pharmacological treatments have been used. Many pharmacological agents like; magnesium, calcium channel blockers, opioid receptor antagonists, corticosteroids, free radical cleaners, sodium channel blockers, cyclosporin A, N-methyl$\mathrm{d}$-aspartate receptor antagonists, and thyrotropin-releasing hormone are used in the prophylaxis of $\mathrm{SCl}$ (15). Reperfusion occurs in 1-2 days following $\mathrm{SCl}$. While the oxygen provided by the reperfusion ensures neural revival, catalysis some enzymatic oxidative reactions at the same time. Reactive oxygens resulted from oxidation reaction, causes DNA fragmentation by starting apoptosis (16). In one of their studies, Lee et al. (17) had applied cilostazol after they had occluded the middle cerebral artery for $2 \mathrm{~h}$. From the samples obtained after 24-48 h of reperfusion, they realized that the DNA fragmentation has been significantly suppressed. It has been declared that, DNA chain breakdown is elicited by excessive poly(ADP-ribose) polymerase (PARP) activity which is a nuclear protein, resulting from ischemia/reperfusion. Thus, leading to necrosis (18). In another study, it is been determined by an enzyme analysis performed that with a low $\mathrm{IC}_{50}$ value of cilostazol, PARP is inhibited. Besides, cilostazol reduced the PARP activity in the rat's cerebral cortex exposed to ischemicreperfusion damage and improved the product of activated PARP (19). Matsumoto et al. (20) reported that cilostazol inhibits the procoagulant activity caused by thrombin and this inhibition

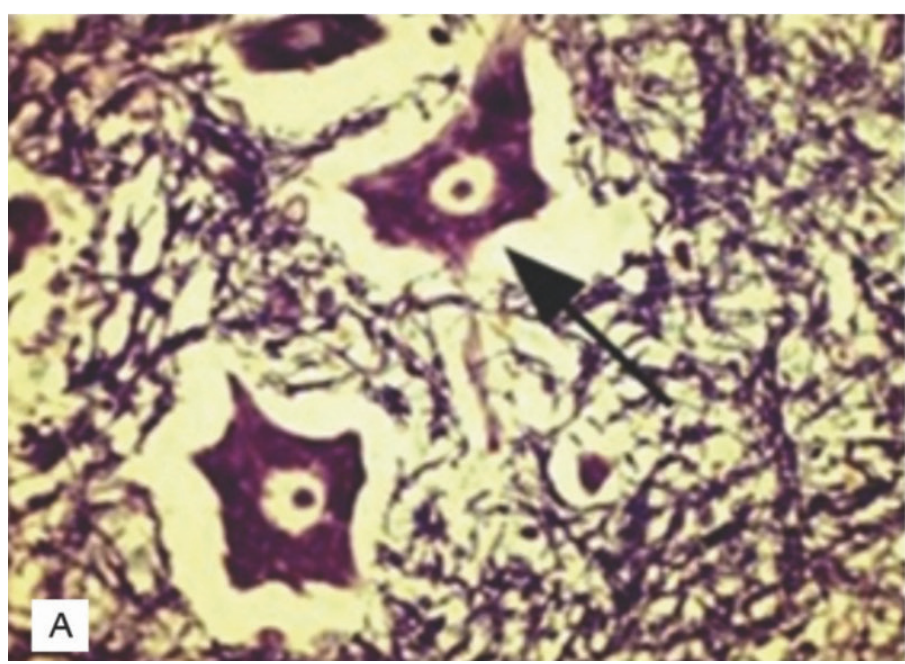

is dependent on cilostazol concentration. With various studies, it has been disclosed that cilostazol has a protective effect against damages caused by transient or chronic cerebral ischemia. It is been revealed by the studies performed in rats that, cilostazol inhibited apoptotic and oxidative cell death, decreased gray and white matter damage thus substantially decreased ischemic brain infarction after $24 \mathrm{~h}$ from focal cerebral ischemia $(21,22)$. With their studies performed in rats, Lee et al. (23) have scanned with magnetic resonance imaging that cilostazol had decreased the brain edema caused by ischemic infarction. Cilostazol prevented cognitive disorder devisal in rats where chronic cerebral hypoperfusion had been created with common carotid artery ligation and protected rats from the formation of white matter lesions (24).

The rat model used in our study was inspired gy the rat model of LeMay et al. (9). The rat model involving aortic clamping is well established and has been previously used for testing the potential neuroprotective effect of drugs (25). In all rats where aortic cross clamp have been applied under normothermia, the observed paraplegia paced quite heavily. Thus, the study has a high repeatability ratio. The arterial vascularization of the spinal cord is very similar in rats. Both have heterosegmental aorta and some anterior radicular arteries (26). Recent experiments revealed that $45 \mathrm{~min}$ of aortic occlusion resulted in complete loss of evoked motor potentials and paraplegia (27). Thus, it is likely that the marked reduction in neuronal damage was affiliated to improved spinal cord function. The histopathological evaluation includes neuronal and axonal damage as well as microglial infiltration. The control group had no spinal injury. Interestingly, the cilostazol-treated group has significantly better histopathological results comparted to the

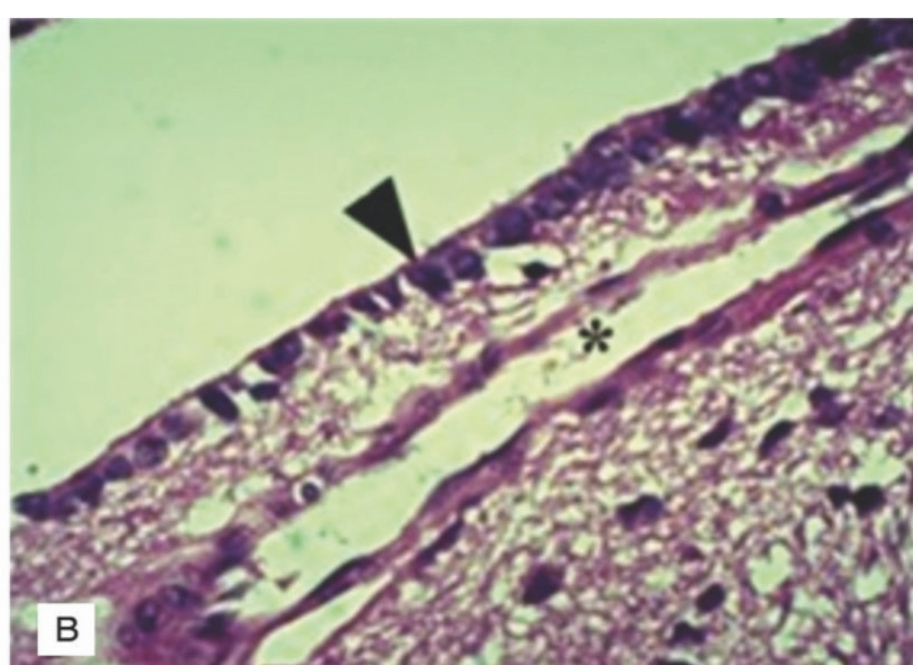

Figure 3. In group 3 (cilostazol group); (A) normal nerve cells (arrow), (B) almost normal ependymal cells (arroehead) and vascular structure $\left({ }^{*}\right)$ are observed. (E) Luxol fast blue (Kluver Berrare) stain x100; (B): hematoxylin \& eosin stain x100; insert: x400 
sham-operated group. These results suggest that cilostazol may also have beneficial effects in protecting the intact and fully healthy spinal cords. It is believed that this effect is achieved by reducing oxidative stress. This study also evaluated the motor and sensory functions in the hind limbs of rats during the $24^{\text {th }}$ and $48^{\text {th }}$ hour of reperfusion, using the Tarlov scale and the LeMay score. Regarding postoperative $24^{\text {th }}$ and $48^{\text {th }}$ hour measurements, both LeMay and Tarlov scores have been ascertained as high in the group treated with cilostazol with respect to the ischemia group. However, when the control group is compared with the cilostazol treatment group, it is been ascertained that there is no difference in Tarlov scores obtained in $24 \mathrm{~h}$.

As a result of this study, it could be assumed that; the motor functions of hind limbs of rats which had received cilostazol treatment, are healed with respect to the neurological examination done on rats after ischemic-reperfusion. With reference to these results, our hypothesis has been verified. As neurological scores of the mice in the control group were higher with respect to the cilostazol group, we think that cilostazol alone is not sufficient for the treatment of motor function disorders caused by the SCl-reperfusion damage. The beneficial effect of cilostazol was also confirmed by a histopathological study.

\section{Study Limitations}

In this study, only functional outcomes and histopathological parameters were evaluated. The lack of biochemical and immunohistochemical assessment is the major pitfall of our study.

\section{CONCLUSION}

In a clinically relevant rat model of aortic cross-clamping, cilostazol given before ischemia markedly reduced morphological spinal cord injury. It could be said that cilostazol might have a healing effect on the motor functions in rats caused by the spinal cord damage as a result of ischemic-reperfusion, though relying on the literature evidence bespoken. However, more scientific research is needed on this subject.

\section{Ethics}

Ethics Committee Approval: Istanbul University Animal Experiments Local Ethics Committee approval were obtained during the study (decision no: 145, date: 09.11.2009).

Informed Consent: There is no need.

\section{Authorship Contributions}

Surgical and Medical Practices: Ü.K.K., G.E.S., Concept: Y.K., Design: Y.K., Data Collection or Processing: Ü.K.K., Analysis or Interpretation: G.E.S.., Literature Search: Ü.K.K., Writing: Ü.K.K., G.E.S.

Conflict of Interest: No conflict of interest was declared by the authors.

Financial Disclosure: The authors declared that this study received no financial support.

\section{REFERENCES}

1. Gilling-Smith GL, Worswick L, Knight PF, Wolfe JH, Mansfield AO. Surgical repair of thoracoabdominal aortic aneurysm: 10 years' experience. $\mathrm{Br}$ J Surg 1995;82:624-9.

2. Lintott P, Hafez HM, Stansby G. Spinal cord complications of thoracoabdominal aneurysm surgery. Br J Surg 1998;85:5-15.

3. Mauney MC, Blackbourne LH, Langenburg SE, Buchanan SA, Kron IL, Tribble CG. Prevention of spinal cord injury after repair of the thoracic or thoracoabdominal aorta. Ann Thorac Surg 1995;59:245-52.

4. Jaeschke H. Preservation injury: mechanisms, prevention and consequences. J Hepatol. 1996;25:774-80.

5. Kimura Y, Tani T, Kanbe T, Watanabe K. Effect of cilostazol on platelet aggregation and experimental thrombosis. Arzneimittelforschung 1985;35:1144-9.

6. Matsumoto M. Cilostazol in secondary prevention of stroke: impact of the cilostazol stroke prevention study. Atheroscler Suppl 2005;6:33-40.

7. Douglas JS Jr, Holmes DR Jr, Kereiakes DJ, Grines CL, Block E, Ghazzal ZM, et al. Coronary stent restenosis in patients treated with cilostazol. Circulation 2005;112:2826-32.

8. Tarlov IM, Klinger H. Spinal cord compression studies. II. Time limits for recovery after acute compression in dogs. AMA Arch Neurol Psychiatry 1954;71:271-90.

9. LeMay DR, Neal S, Neal S, Zelenock GB, D'Alecy LG. Paraplegia in the rat induced by aortic cross-clamping: model characterization and glucose exacerbation of neurologic deficit. J Vasc Surg 1987;6:383-90.

10. Genovese T, Cuzzocrea S. Role of free radicals and poly(ADP-ribose) polymerase- 1 in the development of spinal cord injury: new potential therapeutic targets. Curr Med Chem 2008;15:477-87.

11. Christie SD, Comeau B, Myers T, Sadi D, Purdy M, Mendez I. Duration of lipid peroxidation after acute spinal cord injury in rats and the effect of methylprednisolone. Neurosurg Focus 2008;25:E5

12. Kamencic H, Griebel RW, Lyon AW, Paterson PG, Juurlink BH. Promoting glutathione synthesis after spinal cord trauma decreases secondary damage and promotes retention of function. FASEB J 2001;15:243-50.

13. Kaptanoglu E, Solaroglu I, Okutan O, Surucu HS, Akbiyik F, Beskonakli E. Erythropoietin exerts neuroprotection after acute spinal cord injury in rats: effect on lipid peroxidation and early ultrastructural findings. Neurosurg Rev 2004;27:113-20.

14. Diaz-Ruiz A, Rios C, Duarte I, Correa D, Guizar-Sahagun G, Grijalva I, et al. Lipid peroxidation inhibition in spinal cord injury: cyclosporin-A vs methylprednisolone. Neuroreport 2000;11:1765-7.

Peer-review: Externally peer-reviewed. 
15. Kochhar A, Zivin JA, Lyden PD, Mazzarella V. Glutamate antagonist therapy reduces neurologic deficits produced by focal central nervous system ischemia. Arch Neurol 1988;45:148-53.

16. Bredesen DE. Neural apoptosis. Ann Neurol 1995;38:839-51.

17. Lee JH, Kim KY, Lee YK, Park SY, Kim CD, Lee WS, et al. Cilostazol prevents focal cerebral ischemic injury by enhancing casein kinase 2 phosphorylation and suppression of phosphatase and tensin homolog deleted from chromosome 10 phosphorylation in rats. J Pharmacol Exp Ther 2004;308:896-903.

18. Ducroca S, Benjelloun N, Plotkine M, Ben-Ari Y, Charriaut-Marlangue C. Poly(ADP-ribose) synthase inhibition reduces ischemic injury and inflammation in neonatal rat brain. J Neurochem 2000;74:2504-11.

19. Lee JH, Park SY, Shin HK, Kim CD, Lee WS, Hong KW. Poly(ADP-ribose) polymerase inhibition by cilostazol is implicated in the neuroprotective effect against focal cerebral ischemic infarct in rat. Brain Res 2007;1152:182-90.

20. Matsumoto Y, Marukawa K, Okumura H, Adachi T, Tani T, Kimura Y. Comparative study of antiplatelet drugs in vitro: distinct effects of cAMP-elevating drugs and GPIIb/IIla antagonists on thrombin-induced platelet responses. Thromb Res 1999;95:19-29.

21. Choi JM, Shin HK, Kim KY, Lee JH, Hong KW. Neuroprotective effect of cilostazol against focal cerebral ischemia via antiapoptotic action in rats. J Pharmacol Exp Ther 2002;300:787-93.
22. Honda F, Imai H, Ishikawa M, Kubota C, Shimizu T, Fukunaga M, et al. Cilostazol attenuates gray and white matter damage in a rodent model of focal cerebral ischemia. Stroke 2006;37:223-8.

23. Lee JH, Lee YK, Ishikawa M, Koga K, Fukunaga M, Miyakoda G, et al. Cilostazol reduces brain lesion induced by focal cerebral ischemia in rats--an MRI study. Brain Res 2003;994:91-8.

24. Watanabe T, Zhang N, Liu M, Tanaka R, Mizuno Y, Urabe T. Cilostazol protects against brain white matter damage and cognitive impairment in a rat model of chronic cerebral hypoperfusion. Stroke 2006;37:153945.

25. Lang-Lazdunski L, Heurteaux C, Mignon A, Mantz J, Widmann C, Desmonts J, et al. Ischemic spinal cord injury induced by aortic crossclamping: prevention by riluzole. Eur J Cardiothorac Surg 2000;18:17481.

26. Kanellopoulos GK, Kato H, Hsu CY, Kouchoukos NT. Spinal cord ischemic injury. Development of a new model in the rat. Stroke 1997;28:2532-8.

27. Meylaerts SA, De Haan P, Kalkman CJ, Jaspers J, Vanicky I, Jacobs MJ. Prevention of paraplegia in pigs by selective segmental artery perfusion during aortic cross-clamping. J Vasc Surg 2000;32:160-70.

\begin{tabular}{|c|c|c|}
\hline \multicolumn{3}{|c|}{ Appendix 1. Spinal performance scale } \\
\hline Variable & & Score \\
\hline \multirow{5}{*}{ Walking with lower extremities } & Normal (symmetrical and coordinated ambulation) & 4 \\
\hline & Toes flat under body when walking. but ataxia present & 3 \\
\hline & Knuckle walking & 2 \\
\hline & Movement in lower extremities but inability to knuckle walk & 1 \\
\hline & No movement drags lower extremities & 0 \\
\hline \multirow{4}{*}{ Horizontal rope } & Grasps rope and pulls up with lower extremity & 3 \\
\hline & Grasps rope without pulling & 2 \\
\hline & Unable grasp rope & 1 \\
\hline & Does not raise lower extremity & 0 \\
\hline \multirow{4}{*}{$45^{\circ} \mathrm{C}$ Bar } & Grasps bar for $>10 \mathrm{~s}$ & 3 \\
\hline & Grasps bar for $5-10 \mathrm{~s}$ & 2 \\
\hline & Grasps bar for $<5 \mathrm{~s}$ & 1 \\
\hline & No attempt to grasp bar & 0 \\
\hline \multirow{3}{*}{ Pain sensation } & Normal. withdrawal to toe pinch & 2 \\
\hline & Squeals to toe pinch but does not withdraw & 1 \\
\hline & No reaction to toe pinch & 0 \\
\hline \multirow{4}{*}{ Rotating screen } & Grasps screen to $180^{\circ}$ for $>5 \mathrm{~s}$ & 3 \\
\hline & Grasps screen to $180^{\circ}$ for $<5 \mathrm{~s}$ & 2 \\
\hline & Grasps screen past $270^{\circ}$ but not to $180^{\circ}$ & 1 \\
\hline & Falls from vertical screen & 0 \\
\hline \multicolumn{2}{|l|}{ Total score } & 15 \\
\hline
\end{tabular}

